\title{
Vislumbrar de forma Mística
}

\section{Glimpse in a Mystical way}

\author{
Gilberto Palma Ramírez ${ }^{a}$, Johali Priscila Flores Bustillos ${ }^{b}$.
}

\begin{abstract}
:
Mystical experiences occur in practically all cultures and in all eras. Each of us is prone to the possibility of having a mystical experience. It is, therefore, a phenomenon inherent to the human condition, which is not necessarily linked to religious contexts. That is why the mystical experience can emerge both in profane and sacred places. Psilocybin mushrooms help us to glimpse in a mystical way, psilocybin opens access to the visionary world, does not cause hallucination, does not have the ability to create new and different images of the world, visions have a reference in the world and in the life of person. Psilocybin is the classic psychedelic that ranks highest in complete or introverted mystical experiences.
\end{abstract}

\section{Keywords:}

Mystical experiences, glimpse, psilocybin, psilocybin mushrooms, psychedelics

\section{Resumen:}

Las experiencias místicas se presentan prácticamente en todas las culturas y en todas las épocas. Cada uno de nosotros es propenso a la posibilidad de tener una experiencia mística. Es, pues, un fenómeno inherente a la condición humana, que no está necesariamente ligado a contextos religiosos. Es por ello que la experiencia mística puede despuntar tanto en parajes profanos como sagrados. Los hongos psilocibios nos ayudan a vislumbrar de forma mística, la psilocibina abre el acceso al mundo visionario, no provoca alucinación, no tiene la capacidad para crear nuevas y diferentes imágenes del mundo, las visiones tienen un referente en el mundo y en la vida de la persona. La psilocibina es el psicodélico clásico que más alto rankea en experiencias místicas completas o introvertidas.

\section{Palabras Clave:}

Experiencias místicas, vislumbrar, psilocibina, hongos psilocibios, psicodélicos.

\section{Introducción}

Los hongos Agaricomycotina se originaron entre 380 y 960 millones de años, basado en un fósil Archaeomarasmius la edad mínima de los agaricales data en 90 millones de años, en el cretácico medio y es probable que se hayan originado mucho antes. La psilocibina alcaloide aparece durante el mioceno entre 10 y 20 millones de años. ${ }^{7}$

La psilocibina ([3-(2-dimetilaminoetil)-1H-indol-4il] dihidrógeno fosfato) es un alcaloide monoaminoindol, se produce naturalmente en el género Psilocybe de los hongos y forma parte del grupo de las triptaminas. Después de la ingestión, la hidrólisis rápida la desfosforila en psilocina (4-hidroxi-dimetiltriptamina) que actúa como

Autor de Correspondencia, Universidad Autónoma del Estado de Hidalgo, https://orcid.org/0000-0002-7065-5374, Email: gilberto_palma8909@uaeh.edu.mx

b Universidad Autónoma del Estado de Hidalgo, https://orcid.org/0000-0002-4417-477X, Email: yoalifloresbustillos@gmail.com 
un agonista parcial del receptor 5 - hidroxitriptamina $2 \mathrm{~A}(5-$ HT2A). El efecto es dentro de 1 - 2 horas de ingesta oral, que dura aproximadamente 4 - 6 horas. ${ }^{14}$

Todos los animales con simetría facial de izquierda a derecha, incluidos los insectos, producen serotonina, así como algunas plantas y hongos. Los psilocibios mimetizaron en forma de psilocina la serotonina para insectos, a través de la transferencia horizontal de genes. Los hongos intercambian ADN involucrando como transportadores a insectos, jaqueando el cerebro del transportador en este caso de las termitas evitando que consuman madera, así los psilocibios inclinan la balanza a su favor en la descomposición de lignina. Los hongos psilocibios evolucionaron para convertirse, si no en insecticidas, si en codificadores de insectos. $^{18}$

\section{Efectos de los psilocibios en la consciencia}

En humanos al receptar la psilocina, ésta no causa falla en el proceso perceptual, más bien descodifica la realidad limitada de nuestros cinco sentidos. Estamos acostumbrados a habitar un mundo del cual percibimos solo una fracción de lo real, del resto somos parcialmente conscientes.

Lejos de generarnos una ilusión, consumir un psicodélico estaría desnaturalizando nuestras ilusiones permanentes: el 'yo' no sería más que otra ilusión de nuestro cerebro. En este sentido la mente nos escatima la realidad, el consumo de psicodélicos lo pone en evidencia. ${ }^{19}$

Javier Esteban en su presentación del XX Encuentro Eleusino «Plantas de poder y hongos. La experiencia visionaria como consciencia», Nos dice que lo que vemos en ese teatro provocado por la sustancia no es más que las distorsiones del ego, la modulación del ego, la modulación de tu propia percepción, situarte en terrenos próximos a la experiencia de muerte y resurrección, hay una fase purgativa, una fase demoniaca (miedos), conocimiento bastante duro, son experiencias de conocimiento profundo donde tienes que cruzar un estrecho, un paso (fundamentalmente el miedo). Los sueños no permiten la interpretación en tiempo real de lo que estás viendo, mientras que la visión psicodélica si permite la interpretación. Son sustancias de autoconocimiento que nos posicionan en una capa de la realidad, un mundo intermedio. ${ }^{5}$

Los hongos te mandan al infierno hasta que corrijas lo que tienes que corregir y también tienen el potencial de dar una experiencia espiritual como lo refiere Claudio Naranjo. ${ }^{16}$

Los efectos abrasivos de los psicodélicos quizá sean justamente el catalizador terapéutico, y entonces ya no queda claro de repente qué es el efecto secundario y cuál el terapéutico: Salir del estado usual de conciencia y desinhibir cosas y verlo desde afuera, desde otra perspectiva que quizá es ajena. Tal vez ahí reside el beneficio terapéutico de esas sustancias. ${ }^{4}$

Al abrir la puerta sólo para fines terapéuticos, no se está admitiendo que los psicodélicos puedan ser consumidos como herramientas de autoconocimiento sin que deban tener la necesidad de curar algo como lo refiere Enzo Tagliazucchi. ${ }^{11}$

Stanislav Grof dice que los psicodélicos funcionan como amplificadores no específicos, que aumentan la catexis (carga energética) asociada con los profundos contenidos inconscientes de la psique y los hace disponibles para una su procesamiento consciente. ${ }^{16}$

Evocan pensamientos y sentimientos subconscientes, como recuerdos reprimidos, sentimientos sobre circunstancias de la vida, fantasías o miedos profundos. Por lo tanto, si alguien toma la decisión de usar hongos de psilocibina, es importante que esa persona esté preparada. ${ }^{17}$

En cuanto a las diferencias entre la acción de los psicodélicos y los antidepresivos, es que los Inhibidores selectivos en la recaptura de serotonina (ISRS), inducen una respuesta límbica reducida y moderación emocional o embotamiento, probablemente a través de la señalización del receptor 5 -HT1A postsináptico, esto contrasta con el mayor papel para la señalización de 5-HT2AR con psicodélicos, en este caso con psilocibina, haciendo énfasis en la liberación emocional. ${ }^{3}$

Tener sentimientos adormecidos ciertamente puede servir y tener un papel valioso en algunos padecimientos, pero los sentimientos embotados a menudo impiden a los pacientes comprender y tener una perspectiva más holística de su dolor. Por el contrario, los psicodélicos suelen llevar a los participantes a la liberación emocional, comenzando a examinar tanto en lo personal, como las fuentes sociales de su trauma. ${ }^{8}$

La red en modo de defecto (DMN) en modalidad activa incurre en autorreflexión y en reposo en introspección. Juega un rol importante en el constructo del "yo", "ego"., da la identificación, recuerdo de eventos biográficos, pensar en el futuro, adquirir el punto de vista de otras personas y pensar en sí mismos. La hiperactivación de esta "Red" genera pensamientos excesivos, reflexivos pesimistas, propensión hacia emociones negativas y pobre manejo del estrés. La acción de la psilocibina, un agonista del receptor 5-HT2A, ha sido asociada a una desactivación de esta "Red". Una de sus principales funciones correspondería a dar una coherencia $u$ orden a la experiencia por lo que una reducción en su actividad es coherente con los reportes subjetivos entregados por los sujetos bajo los efectos de 
psilocibina (se menciona una "fragmentación de la experiencia" o "una experiencia con una cualidad de ensueño"). Todo lo anterior indicaría que una reducción en la actividad de estos ejes cerebrales y áreas asociativas de alto orden corresponden a un tipo de cognición sin restricciones provocada por una desincronización cortical de la DMN. ${ }^{22}$

La psilocibina promueve una mayor activación en la corteza auditiva bilateral, corteza somatosensorial, corteza superior parietal, corteza asociativa visual izquierda y el polo occipital. Asimismo, se observó una alta correlación entre el nivel de viveza del recuerdo y la activación de las áreas cerebrales mencionadas anteriormente (usualmente asociadas a viveza en la recolección de recuerdos biográficos), facilitando el acceso a experiencias pasadas, asociadas a traumas y experiencias negativas, como también a una recolección más vívida de recuerdos autobiográficos positivos. Esto se da por la desinhibición de los lóbulos temporales mediales, cuya actividad se ha evidenciado durante flashbacks en casos con trastorno de estrés postraumático. $^{22}$

El lóbulo temporal medial, que se ocupa de la memoria visual y la interpretación. La psilocibina interrumpe sus procesos inhibitorios generando un bombardearlo con imágenes sin permitir su procesamiento. $^{21}$

En 1996 la Dra. Jill Bolte Taylor sufrió un derrame cerebral en el hemisferio izquierdo, experimentó una especie de euforia ya que solo le quedaban funciones del hemisferio derecho. Perdió su sentido de sí misma, pero también eliminó el estrés de su vida o, como ella misma dice, "37 años de equipaje emocional". "Imagina lo que sería estar totalmente desconectado de tu charla cerebral", dijo. "Sentí una sensación de paz". Taylor dice que el hemisferio derecho es como un procesador paralelo y el izquierdo es uno serial. El derecho existe sólo en el aquí y el ahora, y piensa en imágenes: mientras que el izquierdo es lineal, analiza y organiza conforme al pasado y proyecta hacia el futuro, es responsable de la sensación del "yo soy" y, por lo tanto, de la sensación de estar separados de las cosas. ${ }^{2}$

\section{Vislumbrar de forma Mística}

Gastón Guzmán logra hacer la precisión del término usado para distinguir a los hongos con psilocibina, mal llamados: Teonanacatl, el término correcto es Teo-tlacuilnanácatl. Teotl: es energía, esencia o fuerza, tlacuil: significa pintor, precisamente fueron los tlacuilos los que dibujaron los códices y nanácatl: carne o cuerpo. Teotlacuilnanácatl sería: hongo o cuerpo de energía, esencia o fuerza, que pinta o describe a través de visiones. ${ }^{15}$

Los hongos psilocibios nos ayudan a vislumbrar de forma mística. Los psicodélicos abren el acceso al mundo visionario, no tienen la capacidad para crear nuevas y diferentes imágenes del mundo, no son una alucinación, las visiones tiene un referente en el mundo y en la vida de la persona. Para nuestra cultura occidental "ver" significa únicamente mirar el mundo exterior, pero para el hombre tradicional ver también comprende el mundo interior, que nosotros calificamos como falso, fantasioso y compuesto por alucinaciones. No hay duda: Tenemos una idea muy distinta de eso que llamamos realidad y de lo que en ella es posible que ocurra. ${ }^{9}$

A través de nuestros limitados aditamentos sensoriales para captar el exterior definimos una realidad limitante, esta experiencia de la realidad que es captada por la percepción es ilusoria. El cuerpo se ve a sí mismo en un único campo perceptivo. El cuerpo despojado de sus límites, es capaz de transcenderse y penetrar lo invisible, y de esta forma vislumbra. ${ }^{20}$

Mística deriva del griego "cerrado, arcano o misterioso", arcano significa: secreto. Es donde se llega al grado máximo de unión del alma humana a lo sagrado, durante la existencia terrenal. Designa un tipo de experiencia muy difícil del alcanzar. Aunque raras veces se da de forma "espontánea".

Se presenta prácticamente en todas las culturas y en todas las épocas. Todo sujeto es propenso a la posibilidad de tener una experiencia mística. Es, pues, un fenómeno inherente a la condición humana, que no está necesariamente ligado a contextos religiosos. Es por ello que la experiencia mística puede despuntar tanto en parajes profanos como sagrados. ${ }^{20}$

En la experiencia mística tradicional existen múltiples formas para obtenerla, como: los ayunos, flagelaciones, sangrías, aislamiento, privación del sueño, privación sensorial meditación, danzas, posturas corporales, respiración, rutinas ascéticas de austeridad y desapego al mundo material. Son algunos de los modos de acceso para generar el contacto con el gran espíritu, y obtener la visión. Y se dan como ritos de iniciación o de paso dando muerte a la niñez, renaciendo y trascendiendo a una adultez con la visión en la totalidad del espíritu.

Estas vías de acceso tradicionales a la experiencia mística son tan dolorosas y azarosamente largas, y por desgracia no siempre garantizan el resultado. Pero una vez dándose, frecuentemente llegan a presentar una experiencia mística completa llamada introvertida, que también es sufrida por el sujeto al experimentar cambios en todos los aspectos de su integridad humana. Este es el precio que se tiene que pagar al enfrentarse con "dios"., inflamarse y unirse místicamente a él. ${ }^{10}$ 
Robert Master y Jean Houston encuentran que en el consumo de psicodélicos se obtiene principalmente lo que definen como: Misticismo cosmológico. - Experiencia estática de naturaleza y proceso, que deja al sujeto con la sensación de haber tenido importantes visiones interiores, así como de haberse identificado con la naturaleza fundamental y la estructura del universo. ${ }^{10}$

Raras veces transforma al individuo, ya que en limitadas ocasiones realiza el encuentro con lo que se percibe como dios o el ser supremo. Aquí el sujeto expresa la persistencia del estado de energía, en la naturaleza. Más, que la plenitud de la deidad o divinidad descritas en una experiencia mística completa. ${ }^{10}$

Es útil para reducir el miedo a la muerte, pero carece de muy poco valor práctico cuando se trata de preocupaciones más mundanas como la capacidad de afrontamiento 0 incluso en tomar decisiones para direccionar su vida. ${ }^{10}$

A menudo los individuos sienten que su identidad va más allá de su cuerpo. Quizá sea por esto por lo que el miedo a la muerte fue el más citado y el que más se redujo. ${ }^{6}$

Suelen salir de la experiencia sintiéndose casi iluminados con la claridad de saber la tarea que tienen por hacer, pero no les dura tanto el efecto, a las pocas semanas delatan que la experiencia que tuvieron no fue tan trascendente para generar un cambio profundo. $Y$ vuelven a las andadas, a sus conflictos de siempre.

$Y$ he aquí lo peor, al asociarse esta experiencia con un sentido de autotrascendencia se atribuiría o esperaría un aumento de humildad pero, todo lo contrario, los usuarios de psicodélicos no diferían de los otros grupos en el valor que atribuían a la humildad. ${ }^{12}$

Esto da mucho que pensar, en cuanto a las experiencias místicas inducidas por psicodélicos. La pregunta es ¿Podrían estas experiencias realmente inflar los egos? La respuesta al parecer es, sí.

Pueden llegar a generar en la persona, creencias de superioridad ante los demás, ubicándose a sí mismos como los elegidos, tales individuos buscarían la beatitud o iluminación con la ingesta, mejor dicho, con el consumo regularmente atascado de psicodélicos.

Sospecho que ellos no conocen la frase de Alan Watts que dice así: "Si captas el mensaje, cuelga el teléfono". El estar tanto tiempo pegados al teléfono, genera una falsa euforia dado una pérdida del sentido de la responsabilidad, lo cual puede conducir a orgías de orgullo y auto indulgencia espiritual.

Rick Strassman dice que la experiencia espiritual sola, por repetida que sea, no es una base para convertirse en una buena persona. ${ }^{6}$

Este es el verdadero riesgo: que se nos muestre temprano y sin esfuerzo lo que debiéramos de aprender tarde. Acortar el proceso sin el esfuerzo asociado demeritaría el valor de la experiencia. El peligro sin el trabajo del merecimiento previo sería un embrutecimiento espiritual, nos llevaría a la soberbia.

El misticismo cosmológico puede llegar a convertirse en algunas personas en el inicio del largo sendero místico por recorrer. Si es que así lo deciden y si su humildad y su neurosis les permiten trabajar arduamente para lograrlo.

La psilocibina es el psicodélico clásico que más alto rankea en experiencias místicas completas 0 introvertidas. Roland Griffiths concluye en su estudio que las experiencias místicas ocasionadas por consumo de psilocibina conducen a aumentos en los dominios personales de apertura, basado en el modelo de los cinco factores de personalidad. Refiere que el neuroticismo podría ser el responsable de no permitir experimentar y casi bloquear una experiencia mística. Mientras los otros dominios o factores principalmente el de apertura se beneficia de la experiencia mística, generando mayor flexibilidad. ${ }^{13}$

El neuroticismo se refleja en una propensión hacia la emocionalidad negativa y el pobre manejo del estrés. El neuroticismo está asociado con la vulnerabilidad a la psicopatología, potencialmente a través de apoyar interacciones negativas con el medio ambiente y una tendencia hacia la reactividad negativa a los estresores ambientales. $^{1}$

James Fadiman refiere que los psicodélicos fertilizan tu experiencia de vida de modo que pueda crecer algo nuevo. Pero si no tienes mucho abono, puede que no te salga gran cosa, estas sustancias son herramientas de aprendizaje. Y añade: los psicodélicos no son adictivos, jamás lo fueron. ${ }^{6}$

La psilocibina es un psicodélico clásico que al incidir en el sistema serotoninérgico no produce adicción. La experiencia con psilocibios es por lo general intensa, física y mentalmente difícil, estas condiciones determinan que las personas limiten su frecuencia de uso, muchas no vuelven a sentir deseos de repetirlas durante años o incluso nunca. ${ }^{6}$

Walter Terence Stace en su estudio clásico de misticismo de los años 60, hizo posible la operacionalización de este fenómeno en componentes esenciales para su estudio. Las clasifica en introvertida y extrovertida. Refiere que la experiencia extrovertida es enajenada por los sentidos a través de los objetos y es considerada una preparación para el auténtico peregrinaje interno que culmina con la experiencia mística introvertida. La extrovertida difiere de la introvertida al carecer solamente de las dos primeras características. $^{10}$

Stace sugiere 7 características en los estados místicos:

1.- La conciencia unitaria

2.- Debe ser no espacial ni temporal la experiencia. 
3.- Da una sensación de objetividad o realidad.

4.- Sentimientos de bendición, alegría, paz, felicidad

5.- Sentir que lo captado es sagrado, santo o divino.

6.- Hay paradojas.

7.- Afirmación de los místicos de que es inefable.

En la experiencia mística introvertida o completa, se llega a un estado tan profundo conocido como misterio del plano integral que es experimentado como el origen de la realidad. Conceptos tan complejamente sesudos en el argot de la teología conocidos como la esencia primordial y el último fondo del ser resultan para el místico introvertido completamente claros y sencillos de entender.

En la experiencia mística tradicional introvertida ajena a los psicodélicos, tanto en la variedad oriental como en la occidental hay un largo y arduo proceso para vaciar gradualmente la mente de todo su contenido empírico, de todas sus asociaciones, las sensaciones, las imágenes, los símbolos. Hasta que la mente se convierte en un vacío virtual que puede ser llenado con el vacío místico, alcanzando la pura esencia de la unidad indiferenciada, lo que se conoce como el uno sin el dos.

Pero en la experiencia psicodélica sucede lo contrario, se genera la infinitud oceánica. Aquí la consciencia se expande y llega al exterior para ajustarse a una riqueza de fenómenos sin precedentes en la experiencia del sujeto. El contenido empírico de su mente se vitaliza, vibra en la multiplicidad, y todo el conocimiento se incrementa con una intensidad que parece excesiva para poder ser contenida. Entonces, al cruzar el umbral integral, la consciencia, de forma brusca y espontáneamente, se contrae, estrechándose hacia un punto focal de conocimiento, que al ser demasiado compacto estalla en un estado místico de la única realidad del uno. oceánica:

Esto cumple con los 4 criterios de la infinitud

1.- Perspicacia

2.- Estado de felicidad

3.- Experiencia espiritual

4.- Experiencia de unidad.

Resulta interesante que, de acuerdo con informes previos, la ocurrencia y la intensidad de los fenómenos psicodélicos de infinitud oceánica, presente comúnmente en las experiencias de tipo místico, y la disolución del ego, algo similar a la ansiedad, predecirían resultados positivos a largo plazo, mientras que los efectos perceptivos sensoriales prácticamente no tendrían un valor predictivo.

En el futuro, el tratamiento con psicodélicos podría ser de importancia para la psiquiatría y algunas de estas experiencias pueden ayudar a determinar la eficacia del tratamiento. ${ }^{14}$

\section{Referencias}

[1] Barrett F, Johnson M, Griffiths R. Neuroticism is associated with challenging experiences with psilocybin mushrooms. Pers Individ Dif [Internet]. 2017 [citado 11 octubre 2020];(15):155-160. Disponible en: https://pubmed.ncbi.nlm.nih.gov/28781400/

[2] Bolte J. El derrame de iluminación. USA: TED talks; 2008.

[3] Carhart-Harris R, Goodwin G. The Therapeutic Potential of Psychedelic Drugs: Past, Present, and Future.

Neuropsychopharmacology [Internet]. 2017 [citado 10 octubre 2020];(42):2105-2113. Disponible en:

https://pubmed.ncbi.nlm.nih.gov/28443617/

[4] De la Barrera: N. La búsqueda del físico Enzo Tagliazucchi: "De la ayahuasca al LSD, la sociedad occidental no sabe qué hacer con la psicodelia". Almagro [Internet]. 2018 [citado 11 octubre 2020]; Disponible en: https://www.almagrorevista.com.ar/la-busqueda-delfisico-enzo-tagliazucchi-la-ayahuasca-al-lsd-la-sociedad-occidentalno-sabe-la-psicodelia

[5] Esteban J. «Plantas de poder y hongos. La experiencia visionaria como conciencia». España: Encuentros Eleusinos; 2017.

[6] Fadiman J. Guía del explorador psicodélico. Cómo realizar viajes sagrados de modo seguro. 1. ${ }^{\text {a }}$ ed. México: Océano; 2017.

[7] Froese T, Guzmán G, Guzmán L. On the Origin of the Genus Psilocybe and Its Potential Ritual Use in Ancient Africa and Europe. Economic Botany. 2016 [citado 9 octubre 2020]; 70:103-1114. Disponible en: https://link.springer.com/article/10.1007/s12231-0169342-2

[8] Ginsberg N. R/evolutionary Medicine: Psychedelics, Trauma, and the Pharmaceutical Industry. MAPS Bulletin Spring [Internet]. 2016 [citado 11 octubre 2020];(26):88-101. Disponible en: https://maps.org/news/bulletin/articles/407-bulletin-spring2016/6105-r-evolutionary-medicine-psychedelics,-trauma,-and-thepharmaceutical-industry

[9] Glockner J. De dinosaurios y pajaritos. Elementos [Internet]. 2008 [citado 11 octubre 2020];(71):31-37. Disponible en: https://elementos.buap.mx/directus/storage/uploads/00000002105.pdf

[10] Houston J. Los secretos de la experiencia psicodélica. 2. ${ }^{\text {a ed }}$ Barcelona: Bruguera; 1966.

[11] Lagos L. Colisionadores de consciencia. La diaria [Internet]. 2018 [citado 10 octubre 2020]; Ciencia. Disponible en: https://ladiaria.com.uy/articulo/2018/4/colisionadores-de-conciencia/

[12] Lerner M, Lyvers M. Valores y creencias de los usuarios de drogas psicodélicas: un estudio intercultural. Diario de drogas psicoactivas. 2008;(32):143-147.

[13] Mac Lean K, Johnson M, Griffiths R. Mystical experiences occasioned by the hallucinogen psilocybin lead to increases in the personality domain of openness. Psychopharmacol [Internet]. 2011 [citado 11 octubre 2020];(25):53-61. Disponible en: https://pubmed.ncbi.nlm.nih.gov/21956378/ 
[14] Mendoza J. Revisión de artículos: Psilocibina y el interés científico por los hongos ceremoniales. MedScape. 2018 [citado 9 octubre 2020]; Disponible en:

https://espanol.medscape.com/verarticulo/5903094

[15] Palma G, Pérez D, Hernández M, Rodríguez R. Revisión histórica de los hongos psilocibios. Educación y Salud Boletín Científico Instituto de Ciencias de la Salud Universidad Autónoma del Estado de Hidalgo [Internet]. 2020 [citado 11 octubre 2020];8(16):174-186. Disponible en:

https://repository.uaeh.edu.mx/revistas/index.php/ICSA/article/view/4 $\underline{790 / 7220}$

[16] Puente I. Investigación Y Psicoterapia Psicodélica. Pasado Presente Y Futuro. Los libros de la liebre del diario 2017 [citado 10 octubre 2020];:384. Disponible en:

https://www.elsotano.com/libro/investigacion-y-psicoterapiapsicodelica-pasado-presente-y-futuro_10530187

[17] Psilocybin Mushrooms Fact Sheet. Drug Policy Alliance [Internet]. 2017 [citado 10 octubre 2020];1-5. Disponible en: https://www.drugpolicy.org/sites/default/files/Psilocybin_Mushrooms _Fact_Sheet.pdf

[18] Reynolds H, Vijayakumar V, Gluck-Thaler E, Korotkin H, Matheny $\mathrm{P}$, Slot J. Horizontal gene cluster transfer increased hallucinogenic mushroom diversity. Evolution Letters [Internet]. 2018 [citado 11 octubre 2020];(2):88-101. Disponible en: https://onlinelibrary.wiley.com/doi/full/10.1002/evl3.42

[19] Russo D, Pilatti A, Paglini M, Gurvich D, Cremonte M, Bekinschtein P, Sigman M, Prieto J, Rieznik A, Mansilla J, Damin C, Calvo D, Tagliazucchi E, Zamberlán F, Pautassi R, Oviedo-Joekes E, Godoy J, Cancela L. Un libro sobre drogas. El gato y la caja. 2017 [citado 10 octubre 2020];:352. Disponible en:

https://beta.elgatoylacaja.com/sobredrogas\#taco

[20] Rivera M. El Sentido Numinoso de la Luz [Doctorado]. Universitat de Barcelona; 2015.

[21] Tetiyevsky C. ¿Qué psicodélicos pueden enseñarnos sobre la mente para dormir? CUENTOS. 2018.

[22] Timmermann C. Neurociencias y aplicaciones psicoterapéuticas en el renacimiento de la investigación con psicodélicos. Revista chilena de neuro-psiquiatría [Internet]. 2014 [citado 11 octubre 2020];52(2). Disponible en:

https://scielo.conicyt.cl/scielo.php?script=sci_arttext\&pid=S0717 92272014000200005 